DOI 10.37882/2500-3682.2021.04.12

\title{
ЯЗЫКОВОЕ И КУЛЬТУРНОЕ МНОГООБРАЗИЕ
} ВЕЛИКОБРИТАНИИ

\section{LINGUISTIC AND CULTURAL DIVERSITY OF THE UNITED KINGDOM OF GREAT BRITAIN AND NORTHERN IRELAND}

\section{Kryukova}

Summary: The article deals with the linguistic and cultural diversity of the United Kingdom of Great Britain and Northern Ireland from the point of view of the interaction of Standard English, World Englishes, other official languages of the country and the languages of immigrants. The author notes that the English language proficiency has become a special sociocultural marker, the necessary condition for a successful career and social growth. However, many immigrants living in the communities often have little contact with the outside world and may have little or no use of the English language. Keeping their native language and culture in the foreign country, communicating in their own narrow circle, they are not assimilated by the local population, which causes tension in British society.

Keywords: language, culture, Standard English, World Englishes, migration processes, linguistic and cultural diversity.
$\mathrm{H}$ а протяжении длительного времени и в наши дни Великобритания остается одной из наиболее привлекательных стран для иммигрантов. Высокий уровень жизни, богатые традиции и культура, развитая социальная сфера, относительно мягкий климат являются решающими факторами для переезда в эту страну. Известно, что иммигранты привозят в новую страну свои обычаи и культуру. Но в Великобритании этот процесс отличается от других стран. Нередко английский язык благодаря его популярности и широкому распространению во всем мире сам становится причиной для выбора этого места жительства. Кроме того, среди приезжих много уроженцев бывших колоний Великобритании, которые владеют английским языком и знакомы с ее культурой. Однако есть и те, кто не владеет языком совсем, что, несомненно, вызывает ряд трудностей на этапе ассимиляции. К этому следует добавить, что английский язык не является единственным официальным языком Соединенного Королевства, и народы, проживающие на территории страны, в той или иной степени оказали влияние на язык и культуру страны. При этом следует отметить, что «как в культуре, так и в языке каждого народа присутствуют одновременно общечеловеческий и национальный компоненты. Универсальные значения, одинаково осознаваемые всеми людьми в мире или представителями отдельных культур, создают почву для
Крюкова Людмила Сергеевна

К.филол.н., доцент, Военный университет Министерства обороны Российской Федерации (Москва)

I.s.kryukova@mail.ru

Аннотация: В статье рассматривается языковое и культурное многообразие Соединенного Королевства Великобритании и Северной Ирландии с точки зрения взаимодействия стандартного английского языка, мировых английских языков (World Englishes), других официальных языков страны и языков иммигрантов. Автор отмечает, что владение английским языком стало особым социокультурным маркером, необходимым условием для успешной карьеры и социального роста. Однако многие иммигранты, проживающие на территории общин, часто имеют мало контактов с внешним миром и могут практически не пользоваться английским языком. Сохраняя родной язык и культуру в чужой стране, общаясь в своем узком кругу, они не ассимилируются с местным населением, что вызывает напряженность в британском обществе.

Ключевые слова: язык, культура, стандартный английский язык, мировые английские языки, миграционные процессы, языковое и культурное многообразие.

межкультурной коммуникации, без них межкультурное взаимопонимание было бы в принципе невозможно. В то же время в любой культуре присутствуют специфические культурные значения, закрепленные в языке, моральных нормах, убеждениях, особенностях поведения и т.д.» [2, с. 378$]$.

В современной Великобритании 98 процентов населения в той или иной степени владеют английским языком [4, с. 130]. Кроме того, среди других языков, распространенных в Великобритании, часто встречаются кельтский язык, романские языки и языки иммигрантов из Азии и Европы. В связи с постоянно прибывающим в страну потоком иммигрантов особенно остро встал вопрос языковой компетентности. Иммигранты часто плохо владеют английским языком и с трудом могут читать [5, с. 87]. Об этом свидетельствуют данные, полученные Национальным фондом грамотности - организацией, отвечающей за проведение исследований и мероприятий, сбор средств для повышения уровня грамотности. Низкий уровень языковой компетентности создает препятствия для социализации иммигрантов, вызывает напряженность в британском обществе, поскольку владение английским языком является непременным условием для социализации вновь прибывших граждан. Для решения этой проблемы правительством Великобритании 
созданы курсы английского языка - English for Speakers of Other Languages (ESOL). В качестве преподавателей на курсах работают волонтеры, которые помогают иммигрантам успешно интегрироваться в британское общество.

Однако на повышение языковой компетентности мигрантов оказывает влияние несколько важных факторов. Во-первых, это связь языка с социокультурной сферой. В связи с этим особую важность приобретает изучение языка в контексте истории и культуры. Обращаясь к истории английского языка, можно проследить его развитие, значительные изменения, благодаря которым из языка небольших германских племен он превратился в язык международного общения, на котором говорят около 1,5 миллиарда человек. Вбирая в себя особенности других языков и культур, а также оказывая на них влияние, английский определил свое место в мировой культуре.

Во-вторых, владение английским языком стало особым социокультурным маркером. Во многих странах знание этого языка является преимуществом для успешного продвижения по карьерной лестнице, социального роста. Японское правительство сделало английский язык обязательным предметом. В Великобритании, несмотря на более чем 100 лет, прошедших с написания пьесы «Пигмалион» Бернардом Шоу, произношение по-прежнему является маркером, отражающим принадлежность человека к определенным слоям общества. Хороший английский язык, так называемый «Standard English», распространен в среде интеллектуалов, писателей, журналистов, педагогов и государственных чиновников.

\section{Standard English (СтанАартный английский)}

«Standard English» используется для того, чтобы обозначить как непосредственно использование языка, так и языковой идеал для “хороших» или «образованных» пользователей [15].

При этом стандартный английский имеет ограничения по критерию географического распространения: им владеют образованные жители северной Америки и Великобритании.

Существуют мнения о том, что Standard English используется во всем англоговорящем мире. Однако следует отметить, что стандартный английский язык в Великобритании очень сильно отличается от стандарта языка в США.

Слова и выражения британского варианта Standard English зафиксированы в «Оксфордском английском словаре». Сохраняя стандарты английского языка, оксфордский словарь допускает заимствования, используемые для обозначения технических новинок, новых технологий и явлений. В то же время там редко присутствуют слова из языков тех стран, которые раньше были британскими колониями, как например хинди и суахили. При этом существует две точки зрения на дальнейшее развитие английских языков (World Englishes). Согласно одной из них, эти разновидности английского языка постепенно превратятся в самостоятельные языки на основе английского [4, с. 132]. Сторонники второй теории полагают, что эти варианты будут сближаться, а различия между ними исчезнут [12].

\section{World Englishes (Мировые английские языки)}

В 1980-х годах впервые появился исследовательский интерес к так называемым «разновидностям» английского языка, которые, как правило, обозначали в зависимости от их географического расположения. Например, «валлийский английский», «южноафриканский английский» и др. Описание этих разновидностей происходило с точки зрения произношения, грамматики и лексики, а полученные антологии $[20,21]$ внесли большой вклад в понимание того, как английский язык меняется в глобальном мире.

Типичный способ описания «разновидности» английского языка представляет собой краткий социолингвистический очерк о сообществе, в котором используется данная разновидность языка, и список ее особенностей на фонологическом, грамматическом и лексическом уровне. Обычно данные, на которых основаны эти описания, поступают из больших корпусов: ICE (International Corpus of English) - один из таких амбициозных проектов, направленный на сбор корпусных данных из большого количества географических районов, подчиняющихся одним и тем же критериям сбора, что приводит к получению массива данных, легко сопоставимых между разновидностями.

При этом следует учитывать, что данные, собираемые для таких корпусов, как правило, ограничиваются английским языком. Несмотря на то, что в центре внимания исследователей находятся разновидности английского языка, в настоящее время существует очень мало мест, где английский используется в качестве единственного языка. Чаще всего английский язык сосуществует с другими языками: например, валлийский английский - с валлийским языком, южноафриканский английский - с африкаанс, девятью другими официальными и шестнадцатью разговорными языками [14]. Исследователь сингапурского английского Дж. Леймгрубер отмечает, что этот вариант языка используется вместе с мандарином, малайским, тамильским и множеством разновидностей 
китайского. Отношения между английским и этими языками никогда не сводятся к простому сосуществованию бок о бок. Скорее, говорящие используют их одновременно в большей или меньшей степени, переключаются с одного на другой и обратно и регулярно используют элементы или особенности нескольких языков, чтобы лучше передать определенные значения [13, с. 3-5]. Хотя степень многоязычия у разных носителей различна, «чистого» монолингвизма не существует, если принять во внимание даже символическое знание неанглийских слов или фраз носителями языка в таких условиях.

Феномен кодового переключения хорошо задокументирован, и предпринимались попытки создать базы данных и корпусы фактического кодового переключения: Bangor Siarad Corpus (BSC) является одним из таких примеров, где зафиксировано большое количество естественной речи и исследуется несколько переключений с валлийского на английский и наоборот [19]. Социолингвистический выбор, связанный с переключениями, и социальные значения, которые они передают, в некоторой степени могут быть исследованы на основе этих данных. Однако такой подход не дает возможности оценить их вклад в область мировых английских языков (World Englishes), где переключение кодов часто рассматривается как большая помеха для анализа одноязычных местных английских языков.

Некоторые исследователи отказываются от теории разновидностей английского языка и выделяют их в самостоятельные английские языки (World Englishes) [7, 16, $17,18]$. Смешение различных языковых особенностей из разных языков или их разновидностей является совершенно естественным способом выразить свою мысль во многих ситуациях, которые происходят в современных условиях в концептуально, традиционно и официально одноязычных странах.

При этом следует отметить наличие в самом британском английском большого количества разговорных форм (вариантов) языка. В результате этого местное население приобретает так называемое «двуязычие». Вот как описывает этот феномен исследователь английского языка М. Брэгг, рассказывая о своем детстве, проведенной на северо-западе Англии в графстве Камбрия: «Один (язык) был предназначен для дома и улицы, второй для школы, моего собственного литературного творчества, а затем для университета и для Лондона ...» [3, с. 9]. Особенно важно с его точки зрения, что они «не просто употребляли забытые или отвергнутые «образованными» (людьми) слова, но и произносили их с сильнейшим акцентом» [Там же, с. 8].

К факторам, повлиявшим на появление множества разновидностей английского языка в разных частях мира, можно отнести широкое распространение английского языка в границах британской империи и взаимодействие с языками коренных народов. Согласно В.В. Рудневу, ученые проводят разграничение между World Englishes, активно заимствующими слова из других языков, и World English, который является средством коммуникация в дипломатии, торговле и других сферах международной деятельности [4, с. 131]. Благодаря представителям разных культур, иммигрирующих в Великобританию, английский язык пополняется словами, фразами и конструкциями из World Englishes.

\section{Офишиальные и миноритарные языки}

Кроме английского языка в Великобритании распространены валлийский, ирландский гаэльский и шотландский гаэльский языки. На протяжении нескольких столетий носители этих языков испытывали притеснения со стороны англичан и упорно боролись за сохранение своих языков и культуры [1, с. 118]. В результате распада Британской импелрии и усиления сепаратистских настроений в Уэльсе, Шотланлдии и Ирландии правительство страны стало проводить более мягкую языковую политику. Сначала жителям этих регионов позволили использовать родной язык в судах [22], школах и во время церковных служб [1, с. 119], а затем валлийский язык получил такой же статус, как английский [23, 24]; ирландский язык был официально признан языком Северной Ирландии [8]. Закон о статусе шотландского гаэльского языка был принят только в 2005 г. [10] и лег в основу плана по его восста-новлению, принятого шотландским правилтельством в 2010 году [9].

Однако в настоящее время на территории Великобритании проживают не только англичане, шотландцы, уэльсцы и ирландцы, но и представители стран-бывших колоний Британской империи, государств Европы и Азии. Постоянный рост числа мигрантов, которых уже более 6 миллионов в Великобритании, остро обозначил проблему языковой компетентности для британского общества. Иммигранты, которые, как правило, проживают в общинах, часто имеют мало контактов с внешним миром. Для многих общин характерен активный, но в то же время замкнутый образ жизни. Жители общин выпускают газеты на родном языке, работают в магазинах и организациях вместе со своими соотечественниками, общаясь в своем узком кругу. В качестве примера В.В. Руднев приводит польскую общину в Великобритании, насчитывающую более 1 млн. человек [4, с. 132]. Учитывая большое число польских иммигрантов, поселившихся в Великобритании, с 2004 года некоторые британские банки (Barclays, Nat West) стали предоставлять услуги по обслуживанию банковских карт на польском языке $[11$, c. 49]. 
Кроме того, с 2007 г. в стране работают мусульманские третейские суды, которым разрешено применять нормы исламского права в случае возникновения гражданских споров между мусульманами [6, с. 149].

Таким образом, жители общин могут практически не пользоваться английским языком, проживая на территории Великобритании. Однако для полноценной интеграции в британское общество мигрантам необходим хороший уровень владения английским языком.

Соединенное Королевство Великобритании и Северной Ирландии - многонациональная страна, бывшая колониальная держава, обладающая многовековой историей, традициями и культурой. На протяжении столетий страна распространяла свой язык и культуру на подвластных ей территориях. Благодаря этому в настоящее время существует такое явление как мировые английские языки (World Englishes) - отдельные языки, образовавшиеся в результате взаимодействия английского языка и языков бывших британских колоний, присоединенных стран. Многие носители World Englishes сейчас проживают в Соединенном Королевстве, в свою очередь, обогащая английский язык и культуру лексикой, обычаями, традициями своей страны. Однако серьезные опасения вызывает ситуация с мигрантами, не владеющими английским языком и проживающими в своих закрытых общинах. Владение английским языком - обязательное условие для социальной и культурной интеграции мигрантов в британское общество.

\section{ЛИТЕРАТУРА}

1. Андреева Т.Л., Таловская Б. М. Влияние языковой политики Соединённого Королевства Великобритании и Северной Ирландии на развитие английского, валлийского и гаэльского языков // Вестн. Том. гос. ун-та. История. 2017. №50. URL: https://cyberleninka.ru/article/n/vliyanie-yazykovoy-politikisoedinyonnogo-korolevstva-velikobritanii-i-severnoy-irlandii-na-razvitie-angliyskogo-valliyskogo-i (дата обращения: 15.01.2021).

2. Астафьева 0.Н., Грушевицкая Т.Г., Садохин А.П. Теория культуры: учебное пособие для студентов вузов, обучающихся по направлению «Культурология», по социально-гуманитарным специальностям. - Москва: ЮНИТИ-ДАНА, 2017. - 487 с.

3. Брэгг М. Приключения английского языка. - М.: Альпина нон-фикшн, 2014. - 418 c.

4. Руднев В.В. Английский язык в мультикультурной Великобритании (к проблеме коммуникации и интеграции) // Измерение культурного многообразия. Языковая ситуация, переписи, полевая этностатистика. - Москва: ИЭА РАН, 2019. - С. 130-133.

5. Хан А., Шибаева Е.А. Государственные библиотеки Великобритании во времена жесткой экономии // Библиотековедение, 2014 (1). - C. 86-91. URL: https://doi.org/10.25281/0869-608X-2014-0-1-86-91 (дата обращения: 19.01.2021).

6. Хенкин С.М. Интеграция мусульман в Европе: политический аспект / С.М. Хенкин, И.В. Кудряшова // Полис. Политические исследования, 2015. - № 2. C.137-155.

7. Bruthiaux, P. Squaring the circles: issues in modelling English worldwide // International Journal of Applied Linguistics, 2003. - № 13. - P. 159-78.

8. Good Friday Agreement // Encyclopaedia Britannica, 2014. URL: http://global.britannica.com/topic/Good-Friday-Agreement (access date: 23.01.2021)

9. Gaelic Language Plan // Scottish Parliamentary. URL: https://www.parliament.scot/Gaelic/GaelicLanguagePlan_English.pdf (access date: 20.01.2021).

10. Gaelic Language (Scotland) Act 2005. URL: https://www.legislation.gov.uk/asp/2005/7 (access date: 23.01.2021)

11. Hack-Polay D.D. Migrant Integration: Case for a Necessary Shift of Paradigm //Journal of Identity and Migration Studies, 2008. - Volume 2, №1. - P. 37 -56.

12. Jenkins J. World Englishes. A Resource Book for Students. London, New York, 2003. - 256 p.

13. Leimgruber J.R. The trouble with World Englishes // English Today, 2013. - Volume 29. - P. 3-7.

14. Lewis, M.P. Ethnologue: Languages of the World. Sixteenth edition. Dallas: SIL International, 2009. URL: https://ru.scribd.com/document/358435267/EthnologueLanguages-of-the World-Sixteenth-Edition-PDF (access date: 25.01.2021)

15. Melchers G. World Englishes: An Introduction / Gunnel Melchers, Philip Shaw. - Arnold, 2003. - 229 p.

16. Park J.S.Y., Wee L. The three circles redux: a market-theoretic perspective on World Englishes //Applied Linguistics, 2009. - № 30. - p. 389-406.

17. Pennycook A. The Cultural Politics of English as an International Language. London: Longman, 2007. - 365 p.

18. Seargeant P., Tagg C. English on the internet and a "post-varieties" approach to language // World Englishes, 2011. - № 30 (4). - P. 496-514.

19. Stammers, J., Deuchar, M. Testing the nonce borrowing hypothesis: counter-evidence from English-origin verbs in Welsh // Bilingualism: Language and Cognition, 2012. - №15 (3). - P. 630-643.

20. Trudgill P., Hannah J. International English: A Guide to the Varieties of Standard English. First edition. London: Arnold, 1982. - $176 \mathrm{p}$.

21. Wells J.C. Accents of English. 3 volumes. Cambridge: Cambridge University Press, 1982. - 228 p.

22. Welsh Courts Act 1942. URL: http://www.legislation.gov.uk/ukpga/Ge06/5-6/40/enacted (access date: 27.01.2021).

23. Welsh Language Act 1967. URL: http://www.legislation.gov.uk/ukpga/1967/66/enacted access date: 27.01.2021).

24. Welsh Language Act 1993. URL: http://www.legislation.gov.uk/ukpga/1993/38/contents (access date: 27.01.2021). 